\title{
A EDUCAÇÃO A PARTIR DO FEMINISMO NEGRO
}

\section{EDUCATION FROM BLACK FEMINISM}

\section{Flávia Helena Santos da Silva*}

Resumo: Neste artigo analisa-se o feminismo negro como uma ferramenta antirracista e uma forma de contribuição para a educação. Foram utilizados como base bibliográfica literatura especializada de mulheres negras e de educação decolonial, assim como consultados artigos científicos, selecionados por meio de busca nos bancos de dados do Scielo e Google Scholar. O estudo é baseado no protagonismo e nas resistências das mulheres negras e é um meio de entendimento da formação do feminismo negro, extraindo-se dessa compreensão a relevância da decolonidade do saber. Assim, destacam-se situações das mulheres negras não só em seus movimentos de luta do cotidiano, mas principalmente na linha da intelectualidade, bem como seu lugar de fala e o que esse movimento pode contribuir para a educação brasileira.

Palavras-Chave: Mulher Negra. Identidade. Resistência. Educação.

Abstract: In this article, black feminism is analyzed as an anti-racist tool and a form of contribution to education. Specialized literature of black women and decolonial education was used as a bibliographic base, as well as scientific articles were consulted, selected by searching the Scielo and Google Scholar databases. The study is based on the protagonism and resistance of black women and a means of understanding the formation of black feminism, extracting from this understanding the relevance of the decolonity of knowledge. Thus, situations of black women stand out not only in their daily struggle movements, but mainly in the line of intellectuality, as well as their place of speech and what this movement can contribute to Brazilian education.

Keywords: Black woman. Identity. Resistance. Education.

\footnotetext{
* Advogada. Mestranda em Desenvolvimento Local - Centro Universitário Augusto Motta - UNISUAM. Pós-Graduação em Direito Civil e Processo Civil pela UNISUAM. Pós-Graduanda em Educação das Relações Étnico-Raciais no Ensino Básico (EREREBÀ) pelo Colégio Pedro II. Graduação em Direito pelo Centro Universitário da Cidade (2004). E-mail: fhelenadv35@gmail.com
} 


\title{
1 INTRODUÇÃO
}

O trabalho aborda, de maneira breve, algumas reflexões a partir do movimento feminista negro e como este pode auxiliar na educação da sociedade brasileira como instrumento na luta contra o racismo e sexismo.

Acrescenta-se que a pesquisa visa demonstrar o protagonismo e a resistência das mulheres negras, as quais por muito tempo tiveram suas vozes silenciadas, seus corpos estigmatizados e suas vivências (apesar de sempre construir espaços de fortalecimento e de luta) omitidas desde o período escravagista.

Consubstancia-se que, historicamente, possuíam valor e identidade que thes foram atribuídos e não os que Ihes pertenciam verdadeiramente, com todo o arcabouço rico de cultura, religião e costumes que foram apagados ou silenciados através das atitudes racistas. Por esse viés, o movimento feminista negro é de suma importância para a afirmação de nossa identidade.

Enquanto as pessoas negras forem ensinadas a rejeitar a negritude, nossa história, nossa cultura, como única maneira de alcançar qualquer grau de autossuficiência econômica ou ser privilegiado materialmente, então sempre haverá uma crise na identidade negra. $O$ racismo internalizado continuará a erodir a luta coletiva por autodefinição. Massas de crianças negras vão continuar a sofrer baixa autoestima (HOOKS, 2019, p. 60).

hooks ${ }^{1}$ (2019, p. 62) pontua que: "uma cultura de dominação exige a autonegação de todos os seus cidadãos". E acrescenta ainda que:

\begin{abstract}
Quanto mais marginalizados, mais intensa a demanda. Uma vez que as pessoas negras, especialmente as mais pobres, são bombardeadas por mensagens de que não temos valor, de que não somos importantes, não é de surpreender que caiamos na armadilha do desespero niilista ou nas formas de vício que fornecem um escape momentâneo, ilusões de grandeza e liberação temporária da dor de encarar a realidade. (HOOKS, 2019, p. 62).
\end{abstract}

O estudo vem corroborar com a luta e as resistências a fim de desconstruir a desigualdade.

\footnotetext{
1 bell hooks adotou a grafia de seu nome em letras minúsculas. Para ela, nomes, títulos, nada disso têm tanto valor quanto as ideias.
} 


\title{
2 POR UMA EDUCAÇÃO DECOLONIAL A PARTIR DO FEMINISMO NEGRO
}

Iniciamos esse item justificando nossa opção teórica de reconhecimento e de resistência, através do pensamento das feministas negras que nortearam esse artigo para uma educação antirracista e antissexista na sociedade brasileira.

A autora Bell Hooks, professora acadêmica, feminista negra e ativista social, analisa as condições históricas dos sistemas de dominação, e como raça, gênero e classe estruturam e produzem um imaginário social que associa as mulheres negras ao servilismo doméstico e sexual, como consequência do pensamento escravagista que as percebe como apenas corpo sem mente. Segundo a autora:

(...) O sexismo e o racismo atuando juntos perpetuam uma iconografia de representação da negra que imprime na consciência cultural coletiva a ideia de que ela está neste planeta principalmente para servir os outros. Desde a escravidão até hoje o corpo da negra tem sido visto pelos ocidentais como símbolo quintessencial de uma presença feminina natural orgânica mais próxima da natureza animalística e primitiva (HOOKS, 1995, p. 498).

Para melhor compreender esse movimento feminista negro, analisou-se a educação pela ótica da liberdade, conforme pontua Sen:

\begin{abstract}
Ter mais liberdade para fazer as coisas que são justamente valorizadas é (1) importante por si mesmo para liberdade global da pessoa e (2) importante porque favorece a oportunidade de a pessoa ter resultados valiosos. [...]. Ter mais liberdade melhora o potencial das pessoas para cuidar de si mesmas e para influenciar o mundo, questões centrais para o processo de desenvolvimento. (SEN, 2010, p. 33).
\end{abstract}

Extrai-se da ideia acima que o valor da liberdade se assenta no fato de que o homem pode exercer seu direito de autodeterminação frente às escolhas existentes de acordo com seus ideais e propósitos de vida.

Tonet (2012, p. 33) discorre sobre a educação cidadã crítica que seria uma alternativa, não só para formar indivíduos, mas para, acima de tudo, formar cidadãos, capacitados para atender às novas exigências do processo produtivo, bem como conscientes de seus direitos e dispostos a participar, ativa e criticamente, da construção de uma sociedade mais justa, humana e igualitária.

Vale dizer que o homem é um ser inacabado e em constante busca de desenvolvimento, ser dinâmico de mudança, que encontra na educação o processo para o seu crescimento (ARAGÃO; ROITMAN, 2000, p. 83). Porém, essa educação deve ser contrária à concepção "bancária", onde não há criatividade, transformação 
ou saber (FREIRE, 1987). Na medida em que, segundo o autor, somente o depósito de informações, sem o devido estímulo ao desenvolvimento, elimina o poder criador dos educandos ou o minimiza, promovendo sua ingenuidade e não sua criticidade, satisfazendo, dessa forma, aos interesses dos opressores.

Reymão e Koury (2017) salientam a necessidade de desenvolver as capacidades humanas para que as pessoas possam participar livremente das tomadas de decisões políticas e econômicas. Esse seria o papel da educação, a qual se configura como instrumento capaz de reduzir as injustiças sociais, na medida em que o homem, enquanto ser, é o fim precípuo dentro do processo educacional, que deve ir além dos ditames formais, favorecendo a essencialidade do indivíduo.

A respeito da educação no Brasil, vêm sendo estudados os chamados intelectuais decoloniais. $\mathrm{O}$ termo foi cunhado originalmente por Nelson MaldonadoTorres em 2005 e que significa o movimento de resistência teórico e prático, político e epistemológico, à lógica da modernidade/colonialidade (BALLESTRIN, 2013, p. 105).

Mignolo (2010, p. 14-15) enalteceu e diferenciou pensamento decolonial explicando que:

\begin{abstract}
Colonialidade e descolonialidade introduzem uma fratura entre a pósmodernidade e a pós-colonilaidade como projetos no meio do caminho entre o pensamento pós-moderno francês de Michel Foucault, Jacques Lacan e Jaques derrida e quem é reconhecido como a base do cânone pós-colonial: Edward Said, Gayatri Spivak e Hommi Bhabba. A descolonialidade - em contrapartida - arranca de outras fontes. Desde a marca descolonial implícita na Nueva Crónica y Buen Gobierno de Guamán Porna de Ayala; no tratado político de Ottobah Cugoano; no ativismo e crítica decolonial de Mahatma Ghandi; na fratura do Marxismo em seu encontro com o legado colonial nos Andes, no trabalho de José Carlos Mariátegui; na política radical, o giro epistemológico de Amilcar Cabral, Aimé Césaire, Frantz Fanon, Rigoberta Menchú, Gloria Anzaldúa, entre outros. (MIGNOLO, 2010, p. 14-15, grifo do autor).
\end{abstract}

O raciocínio principal do grupo se baseia em que: "a colonialidade é constitutiva da modernidade, e não derivada" (MIGNOLO, 2005, p. 75). Isto é, "graças à colonialidade, a Europa pode produzir as ciências humanas como modelo único, universal e objetivo na produção de conhecimentos, além de deserdar todas as epistemologias da periferia do ocidente" (OLIVEIRA; CANDAU, 2010, p.17).

As origens da ideia de decolonialidade, como aponta Ballestrin (2013), estavam contidas em Quijano (2000) e Dussel (2000). Quijano (2000) desenvolveu o 
pensamento de colonialidade de poder e Dussel (2000) acrescentou a noção de trans-modernidade:

A modernidade nasce realmente em 1492: essa é a nossa tese. Sua real superação (como subsuntion e não meramente como Aufhebung hegeliana) é a subsunção de seu caráter emancipador racional europeu transcendido como projeto mundial de libertação de sua Alteridade negada: a TransModernidade (como novo projeto de libertação político, econômico, ecológico, erótico, pedagógico, religioso e etecetera) (DUSSEL, 2000, p. 50$51)$.

Maldonado-Torres (2007) conceitua a descolonização como um projeto que:

aspira romper com alógica monológica da modernidade. Pretende fomentar trans-modernidade: um conceito que também deve se entender como um convite ao diálogo e não como um novo universal abstrato imperial. A transmodernidade é um convite apensar a modernidade/colonialidade de forma crítica, desde posições e de acordo com as múltiplas experiências de sujeitos que sofrem de distintas formas a colonialidade de poder, do saber e do ser. A transmodernidade envolve, pois, uma ética dialógica radical e um cosmopolitismo de-colonial crítico (MALDONADO-TORRES, 2007, p. 162).

Oliveira e Candau (2010) explicam que o termo "DE" exprime a ideia de uma insurgência educativa propositiva e não somente denunciativa com a utilização do prefixo "DES". E conceitua pedagogia decolonial como uma maneira de:

(...) expressar o colonialismo que construiu a desumanização dirigida aos subalternizados pela modernidade europeia e pensar na possibilidade de crítica teórica a geopolítica do conhecimento. Esta perspectiva é pensada a partir da ideia de uma prática política contraposta a geopolítica hegemônica monocultural e monoracional, pois trata-se de visibilizar, enfrentar e transformar as estruturas e instituições que têm como horizonte de suas práticas e relações sociais a lógica epistêmica ocidental, a racialização do mundo e a manutenção da colonialidade (OLIVEIRA; CANDAU, 2010).

Sabe-se que tanto os pensamentos decoloniais quanto pós-coloniais têm sua origem em tempos mais remotos, quando os grupos étnicos habitantes desses espaços geográficos subalternizados reclamavam por seu direito à alteridade e de permanecerem dentro de sua esfera cultural (BALLESTRIN, 2013).

Bello (2015 apud OLIVEIRA, 2016, p. 4) atribui que a descolonialidade vai além do caráter geográfico. "É uma transformação epistêmica, de se autocompreender e de respeitar a alteridade de outras culturas" (OLIVEIRA, 2016, p. 4).

O termo decolonial se conecta ainda com o conteúdo do significado de interculturalidade crítica, a qual propõe um giro epistêmico, capaz de produzir novos 
conhecimentos e uma outra compreensão simbólica do mundo, sem perder de vista a colonialidade. Representa a construção de um novo espaço epistemológico que promove a interação entre os conhecimentos subalternizados e os ocidentais, questionando a hegemonia destes e a inviabilização daqueles (WALSH, 2005a).

Criticou também a maneira de como a ciência mantinha a ordem hierárquica racial:

(...) a maneira através da qual a ciência, como um dos fundamentos centrais do projeto Modernidade/Colonialidade, contribuiu de forma vital ao estabelecimento e manutenção da ordem hierárquica racial, histórica e atual, na qual os brancos e especialmente os homens brancos europeus permanecem como superiores. (WALSH, 2007, p. 9 apud OLIVEIRA; CANDAU, 2010, p. 26).

A Autora ainda traz a discussão sobre os conceitos de interculturalidade crítica e sua incidência no campo educacional. Para ela, significava ser a interculturalidade:

\footnotetext{
-Um processo dinâmico e permanente de relação, comunicação e aprendizagem entre culturas em condições de respeito, legitimidade mútua, simetria e igualdade.

- Um intercâmbio que se constrói entre pessoas, conhecimentos, saberes e práticas culturalmente diferentes, buscando desenvolver um novo sentido entre elas na sua diferença.

- Um espaço de negociação e de tradução onde as desigualdades sociais, econômicas e políticas, e as relações e os conflitos de poder da sociedade não são mantidos ocultos e sim reconhecidos e confrontados.

- Uma tarefa social e política que interpela ao conjunto da sociedade, que parte de práticas e ações sociais concretas e conscientes e tenta criar modos de responsabilidade e solidariedade.

- Uma meta a alcançar. (WALSH, 2005b, p. 10-11)
}

Outro estudo da autora destaca que:

O conceito de interculturalidade é central à (re)construção de um pensamento crítico-outro - um pensamento crítico de/desde outro modo -, precisamente por três razões principais: primeiro porque está vivido e pensado desde a experiência vivida da colonialidade [...]; segundo, porque reflete um pensamento não baseado nos legados eurocêntricos ou da modernidade e, em terceiro, porque tem sua origem no sul, dando assim uma volta à geopolítica dominante do conhecimento que tem tido seu centro no norte global. (WALSH, 2005a, p. 25)

Penna (2014) defende que Paulo Freire (1987) já exercia o pensamento decolonial, uma vez que o pensamento do pedagogo vai ao encontro das perspectivas dos intelectuais descolonizadores pois denuncia a trajetória histórica e a realidade opressora que ocorreram pelos diversos tipos de colonização na América Latina. Questiona as metodologias e os aportes teóricos utilizados como 
forma de perpetuar o poder do colonizador e ainda propõe a pedagogia a qual vai formar pensadores críticos, cidadãos cientes da geopolítica do conhecimento e que lutarão por seu direito à alteridade.

Neste entendimento, pode-se observar também mais um caminho para se desconstruir o racismo e o sexismo, na educação brasileira. Como foi o caso da publicação Lei 10.639/03, a qual alterou a Lei n-9.394, de 20 de dezembro de 1996, que estabelecia as diretrizes e bases da educação nacional, para incluir no currículo oficial da Rede de Ensino a obrigatoriedade da temática "História e Cultura AfroBrasileira", além de acrescentar os artigos 26 A e 79 B.

$\mathrm{O}$ artigo 26 A prevê a obrigatoriedade, nos estabelecimentos de ensino fundamental e médio, oficiais e particulares, do ensino sobre História e Cultura AfroBrasileira, e os seus parágrafos preveem:

$\S 1$ 으 conteúdo programático a que se refere o caput deste artigo incluirá o estudo da História da África e dos Africanos, a luta dos negros no Brasil, a cultura negra brasileira e o negro na formação da sociedade nacional, resgatando a contribuição do povo negro nas áreas social, econômica e políticas pertinentes à História do Brasil.

$\S 2$ ○-Os conteúdos referentes à História e Cultura Afro-Brasileira serão ministrados no âmbito de todo o currículo escolar, em especial nas áreas de Educação Artística e de Literatura e História Brasileira. (BRASIL, 2003).

O artigo 79-B incluiu no calendário escolar o dia 20 de novembro como ‘Dia Nacional da Consciência Negra'.

A publicação da Lei representa o resultado da luta antirracista. Pela perspectiva da lei podemos incluir também a discussão do gênero, junto com a raça, como é o caso da história pela ótica da escravizada. Discutir sobre o racismo e sexismo é uma forma de não silenciar os mais diversos preconceitos e discriminações presentes na escola, além de promover relações igualitárias. Ademais, as escolas tradicionais apresentam falhas na medida em que não articulam os conteúdos ministrados em sala de aula, tomada em seus diferentes aspectos e composta pela diversidade de pessoas que compõe a sociedade brasileira.

No mesmo sentido traz-se não só o paradigma positivo da lei, como também é abordada a discussão do feminismo e sua importância na atualidade. E de que maneira serve como mais um instrumento no enfrentamento do sexismo. A pesquisa se propõe ainda a demonstrar a diferença do feminismo negro do feminismo clássico a partir da ótica da decolonialidade, conforme se demonstra a seguir. 
Quijano (2000, p. 342) já relacionava raça, gênero e trabalho. Para ele essa junção constituíram a formação do capitalismo mundial colonial/moderno no século XVI. E essa três interseccionalidades (gênero, raça e classe) foi o ponto fundamental para o encontro do feminismo com o pós-colonialismo na década de 1980. Desse encontro surge o feminismo pós-colonial, o qual não se originou do diálogo entre mulheres acadêmicas do Primeiro e Terceiro Mundo (ASHCROFT; GRIFFITHS; TIFFIN, 2002).

Tal assertiva do parágrafo anterior traz à discussão do feminismo decolonial, onde a crítica se funda no fato de que diferentes ondas do feminismo foram feitas por mulheres brancas de classe média e voltadas para essas. Como por exemplo o feminismo ocidental o qual: "passou a ser acusado por seu universalismo, etnocentrismo, anglo-eurocentrismo, branqueamento e pela negligência de questões coloniais e raciais que atravessam etnias, nacionalidades e geografias" (BALLESTRINI, 2017, p. 1040).

Assim, teve o feminismo decolonial uma preocupação em mostrar a necessidade de se respeitar as diferenças das mulheres indígenas, afrodescendentes e latino-americanas como forma de empoderamento de grupos étnicos que sofrem discriminação tanto pelo processo de racialização, oriundo da Europa, quanto pelo gênero. Contudo este assunto específico comentar-se-á no tópico seguinte.

Entende-se que o feminismo é considerado como movimento de mulheres que lutam pelo alcance de uma sociedade igualitária. Através dele, as mulheres já conquistaram direitos no âmbito social e político, mas pelo feminismo abordar de uma maneira geral a luta de mulheres, houve a necessidade de um recorte mais específico, no caso o feminismo negro. Este surgiu através das especificidades vivenciadas pelas mulheres negras e derruba padrões socialmente naturalizados. No Brasil, esse movimento ganhou força nos anos 1980.

No mesmo entendimento, Collins (2017, p. 51):

Usar o termo "feminismo negro" desestabiliza o racismo inerente ao apresentar o feminismo como uma ideologia e um movimento político somente para brancos. Inserindo o adjetivo "negro" desafia a brancura presumida do feminismo e interrompe o falso universal deste termo para mulheres brancas e negras. Uma vez que muitas mulheres brancas pensam que as mulheres negras não têm consciência feminista, o termo "feminista negra" destaca as contradições subjacentes à brancura presumida do feminismo e serve para lembrar às mulheres brancas que elas não são nem as únicas nem a norma "feministas". 
Como já defendia Gonzaléz (1984) sobre o feminismo afrolatinoamericano, percebeu-se nos estudos que as mulheres negras, para além do compartilhamento de experiências baseadas na escravidão, no racismo e colonialismo, bem como do enfrentamento do racismo e sexismo, partilham também processos de resistências.

Convém destacar que compartilha-se com o entendimento de Gonzalez (1984), quando ela se refere ao "pretuguês", valorizando a linguagem falada pelos povos negros africanos escravizados no Brasil. Dessa maneira propunha a descolonização do conhecimento. Inclusive analisou a figura da mulher negra como sendo a responsável por transmitir valores para a cultura brasileira:

\begin{abstract}
E quando a gente fala em função materna, a gente tá dizendo que a mãe preta, ao exercê-la, passou todos os valores que lhe diziam respeito pra criança brasileira, como diz caio Prado Júnior. Essa criança, esse infans, é a dita cultura brasileira, cuja língua é o pretuguês. A função materna diz respeito à internalização de valores, ao ensino da língua materna e a uma série de outras coisas (GONZALEZ, 1984, p.235).
\end{abstract}

Ribeiro (2017) se alinhando ao entendimento acima, considera que a linguagem é o fator primordial a ser analisado, pois: "constitui um instrumento de forma de manutenção de poder, uma vez que exclui indivíduos que foram afastados das oportunidades de um sistema educacional justo". Ademais, a depender da maneira como é utilizada, poderá ser uma barreira ao entendimento, além de ser um impeditivo para uma educação transgressora (HOOKS, 2013).

Acrescenta-se ao contexto a reflexão de Alcoff (2016) sobre a necessidade de incluir em nossos currículos outros saberes. Pode - se citar como exemplos: o saber de mulheres de terreiros, das mulheres do movimento por luta por creches, das lideranças comunitárias, irmandades negras, dos movimentos sociais.

Hooks (2013), fala sobre a importância da intelectualidade para a mulher negra, ou seja, saber unir o pensamento à prática, já que, em uma sociedade racista e sexista como a brasileira, mulheres negras foram construídas ligadas ao corpo e não ao pensar. Por isso a importância de se ater à identidade social, para demonstrar como essas identidades têm sido historicamente silenciadas e desautorizadas no sentido epistêmico, ao passo que outras são fortalecidas (ALCOFF, 2016).

Assim, neste tópico entenderemos o lugar de fala da mulher negra e a representatividade do feminismo negro e a inclusão destes na educação conforme demonstra-se a seguir. 
Para a filósofa Beauvoir (1980), a mulher foi constituída como o Outro, pois é vista como um objeto. As mulheres negras seriam o Outro do outro, já que não são nem brancas, nem homens, como afirma Kilomba (2012, p. 56):

As mulheres negras foram assim postas em vários discursos que deturpam nossa própria realidade: um debate sobre o racismo onde o sujeito é homem negro; um discurso de gênero onde o sujeito é a mulher branca; e um discurso sobre a classe onde "raça" não tem lugar. Nós ocupamos um lugar muito crítico, em teoria. É por causa dessa falta ideológica, argumenta Heidi Safia Mirza (1997) que as mulheres negras habitam um espaço vazio, um espaço que se sobrepõe às margens da "raça" e do gênero, o chamado "terceiro espaço". Nós habitamos um tipo de vácuo de apagamento e contradição "sustentado pela polarização do mundo em um lado negro e de outro lado, de mulheres." (MIRZA, 1997:4). Nós no meio. Este é, é claro, um dilema teórico sério, em que os conceitos de "raça" e gênero se fundem estreitamente em um só. Tais narrativas separativas mantêm a invisibilidade das mulheres negras nos debates acadêmicos e políticos.

Sobre as mulheres negras, Collins (2016, p. 105) aborda sobre a necessidade de se autodefinirem:

A insistência de mulheres negras autodefinirem-se, autoavaliarem-se e a necessidade de uma análise centrada na mulher negra é significativa por duas razões: em primeiro lugar, definir e valorizar a consciência do próprio ponto de vista autodefinido frente a imagens que promovem uma autodefinição sob a forma de "outro" objetificado é uma forma importante de se resistir à desumanização essencial aos sistemas de dominação. O status de ser o "outro" implica ser o outro em relação a algo ou ser diferente da norma pressuposta de comportamento masculino branco.

Nesse modelo, homens brancos poderosos definem-se como sujeitos, os verdadeiros atores, e classificam as pessoas de cor e as mulheres em termos de sua posição em relação a esse eixo masculino branco. Como foi negada às mulheres negras a autoridade de desafiar essas definições, esse modelo consiste de imagens que definem as mulheres negras como um outro negativo, a antítese virtual da imagem positiva dos homens brancos.

\section{Portando definir-se é essencial para o fortalecimento e a demarcação de possibilidades de transcendência da norma colonizadora, como explica Collins (2016).}

Carneiro (2003, p. 50-51), sobre o feminismo negro, demonstra o olhar sob a ótica das mulheres negras:

Quando falamos do mito da fragilidade feminina, que justificou historicamente a proteção paternalista dos homens sobre as mulheres, de que mulheres estamos falando?

Nós, mulheres negras, fazemos parte de um contingente de mulheres, provavelmente majoritário, que nunca reconheceram em si mesmas esse mito, porque nunca fomos tratadas como frágeis. Fazemos parte de um contingente de mulheres que trabalham durante séculos como escravas nas lavouras ou nas ruas, como vendedoras, quituteiras, prostitutas... Mulheres que não entenderam nada quando as feministas disseram que as mulheres deveriam ganhar as ruas e trabalhar. Fazemos parte de um contingente de 
mulheres com identidade de objeto. Ontem, a serviço de frágeis sinhazinhas e de senhores de engenho tarados.

São suficientemente conhecidas as condições históricas nas Américas que construíram a relação de coisificação dos negros em geral, e das mulheres negras em particular. Sabemos, também, que em todo esse contexto de conquista e dominação, a apropriação social das mulheres do grupo derrotado é um dos momentos emblemáticos de afirmação de superioridade do vencedor. Hoje, empregadas domésticas de mulheres liberadas e dondocas, ou de mulatas tipo exportação. Quando falamos em romper com o mito da rainha do lar, da musa idolatrada dos poetas, de que mulheres estamos falando? As mulheres negras fazem parte de um contingente de mulheres que não são rainhas de nada, que são retratadas como antimusas da sociedade brasileira, porque o modelo estético de mulher é a mulher branca. Quando falamos em garantir as mesmas oportunidades para homens e mulheres no mercado de trabalho, estamos garantindo emprego para que tipo de mulher? Fazemos parte de um contingente de mulheres para as quais os anúncios de emprego destacam a frase: "Exige-se boa aparência".

Quando falamos que a mulher é um subproduto do homem, posto que foi feita da costela de adão, de que mulher estamos falando? Fazemos parte de um contingente de mulheres originárias de uma cultura que não tem Adão. Originárias de uma cultura violada, folclorizada e marginalizada, tratada como coisa primitiva, coisa do diabo, esse também um alienígena para a nossa cultura. Fazemos parte de um contingente de mulheres ignoradas pelo sistema de saúde na sua especialidade, porque o mito da democracia racial presente em todas nós, torna desnecessário o registro da cor dos pacientes nos formulários da rede pública, informação que seria indispensável para avaliarmos as condições de saúde das mulheres negras no Brasil, pois sabemos, por dados de outros países, que as mulheres brancas e negras apresentam diferenças significativas em termos de saúde. Portanto, para nós se impõe uma perspectiva feminista na qual o gênero seja uma variável teórica, mas como afirmam Linda Alcoff e Elizabeth Potter, que não "pode ser separada de outros eixos de opressão" e que não "é possível em uma única análise. Se o feminismo deve liberar as mulheres deve enfrentar virtualmente todas as formas de opressão". A partir desse ponto de vista, é possível afirmar que um feminismo negro, construído no contexto de sociedades multirraciais, pluriculturais e racistas - como são as sociedades latino-americanas -, tem como principal eixo articulador 0 racismo e seu impacto sobre as relações de gênero, uma vez que ele determina a própria hierarquia de gênero em nossas sociedades.

Um dos objetivos do feminismo negro é marcar o lugar de fala de quem as propõe, ou seja, propostas pelas mulheres negras (de suas vivências e perspectivas). É necessário para entender realidades que foram consideradas implícitas dentro da normatização hegemônica. Isto é, entender como o lugar social que certos grupos ocupam restringe oportunidades. Seria um debate estrutural (COLLINS, 1997; RIBEIRO, 2017).

Collins (1997) considera que mesmo pessoas negras de classe média não estão isentas dos efeitos da discriminação de oportunidades geradas pela segregação racial e, por conseguinte, pela discriminação de grupo. O valor de lugar de fala se atribui como direito à existência digna à voz, de poder existir. 
Spivak (2010, p. 126) ensina que grupos subalternos não teriam voz, pois estão num lugar em que suas humanidades não são reconhecidas: "O subalterno não pode falar. Não há valor algum atribuído à "mulher, negra e pobre" como um item respeitoso na lista de prioridade globais. A representação não definhou. A mulher como uma intelectual tem uma tarefa circunscrita que ela não deve rejeitar como floreio".

Todas essas abordagens das autoras acima citadas nos fazem pensar a respeito sobre as resistências das mulheres negras e entender a formação do feminismo negro, além de passar todas as referências e valores para as futuras gerações. Daí se extrai a relevância da decolonidade do saber. Incluindo todo o conteúdo, vai-se diluindo o racismo e consequentemente o sexismo. Por isso destacou-se as situações das mulheres negras não só em seus movimentos de luta do cotidiano, mas principalmente na linha da intelectualidade.

\section{CONSIDERAÇÕES FINAIS}

O protagonismo e o empoderamento também são formas de enfrentamento, quando uma mulher negra ocupa um espaço que lhe é negado. Essas ações manifestam a possibilidade de que seus participantes tomem consciência da realidade em que vivem, dos alcances e limites de suas próprias forças, e, a partir desses movimentos, possam adquirir experiências, propondo novos modelos de organização e luta.

A compreensão do que é ser mulher negra, com olhar além das convenções historiográficas, é desconstruir as representações normativas a partir do lugar de fala dessas mulheres para entender os processos de produção e assimilação dos referenciais construídos por elas.

Podendo-se aprender de todos os conceitos abordados pelos Autores utilizados no texto que a identidade e a diversidade, a qual tentam apagar de nós em todos os segmentos: cultural, religioso etc., foram e são de suma importância como forma de resistência da nossa memória e história até os dias atuais. Apesar de todo racismo e adversidade que a sociedade brasileira branca, patriarcal, hétero e cis impõe, sobrevivemos e lutamos.

O caminho para a luta antirracista é amar a negritude como resistência política, a qual transforma nossas formas de ver e ser e, portanto, cria as condições 
necessárias para que nos movamos contra as forças de dominação e morte que tomam as vidas negras. E, além disso, através da educação (em especial na escola) repassar toda a importância da nossa representatividade, reforçando a nossa identidade e principalmente educando o branco. O que torna a lei 10.639/03 uma aliada que, na prática, abre mais um caminho para eliminação do racismo em nosso país.

\section{REFERÊNCIAS}

ALCOFF, Linda. Uma epistemologia para a próxima revolução. Sociedade e Estado. Brasília, n.1, v.31, jan/abr., 2016. Disponível em: https://goo.gl/bKi4Pu. Acesso em: 1 out. 2019.

ARAGÃO, Selma; ROITMAN, Riva. Educação e desenvolvimento: um despertar para o novo milênio. In: MARCIAL, Danielle; ROBERT, Cinthia; SÉGUIN, Elida (org.). O Direito do desenvolvimento. Rio de Janeiro: Lumen Juris, 2000.

ASHCROFT, Bill; GRIFFITHS, Gareth; TIFFIN, Hellen. The empire writes back: theory and practice in post-colonial literature. London, New York: Routledge, 2002.

BALLESTRIN, Luciana. América Latina e o giro decolonial. Revista Brasileira de Ciência Política, Brasília, DF, n. 11, p.89-117, maio/ago. 2013.

BALLESTRIN, Luciana. Feminismos Subalternos. Estudos Feministas, Florianópolis, v. 25, n. 3, set./dez. 2017.

BEAUVOIR, Simone. O segundo sexo: a experiência vivida. Tradução de Sérgio Millet. 4. ed. São paulo: Difusão Européiea do Livro, 1980.

BRASIL. Lei no 9394/1996, de 20 de dezembro de 1996. Estabelece as diretrizes e bases da educação nacional. Diário Oficial da República Federativa do Brasil. Brasília, DF, 23 dez.1996.

BRASIL. Lei 10.639/2003, de 9 de janeiro de 2003. Estabelece as diretrizes e bases da educação nacional, para incluir no currículo oficial da Rede de Ensino a obrigatoriedade da temática "História e Cultura Afro-Brasileira". Diário Oficial da República Federativa do Brasil. Brasília, DF, 9 jan.2003.

CARNEIRO, Sueli. Enegrecer o feminismo: a situação da mulher negra na América latina a partir de uma perspectiva de gênero. In: ASHOKA EMPREENDEDORES SOCIAIS; TAKANO CIDADANIA (org.). Racismos contemporâneos. Rio de Janeiro: Takano Editora, 2003.

COLLINS, Patricia Hill. O que é um nome?: Mulherismo, Feminismo Negro e além disso. Cadernos Pagu, n. 51, p. 2007. Disponível em: http://www.scielo.br/pdf/cpa/n51/1809-4449-cpa-18094449201700510018.pdf. 
Acesso em 23 fev.2020

COLLINS, Patricia Hill. Aprendendo com a outsider within: a significação sociológica do pensamento feminista negro. Sociedade e Estado, v. 31, n. 1, p.99-127, 2016.

COLLINS, Patricia Hill. Comentário sobre o artigo de Hekman "Truth and Method: Feminist Standpoint Theory Revisited: Onde está o poder? Signs, v. 22, n. 2, p. 375381, 1997. Tradução de Juliana Borges.

DUSSEL, Enrique. Europa, modernidad y eurocentrismo. In: LANDER, Edgardo (coord.). La colonialidad del saber: eurocentrismo y ciencias sociales, perspectivas latino-americanas. Buenos Aires: Clacso, 2000.

ESCOBAR, Arturo. Mundos y conhecimientos de outro mundo: o programa de investigación de modernidade/colonialidad latinoamenricano. Revista Tabula Rasa, n. 4 , p. 50-161, 2003.

FREIRE, P. Pedagogia do oprimido. 17.ed. Rio de Janeiro: Paz e terra, 1987.

GONZÁLES, Lélia. Racismo e sexismo na cultura brasileira. Revista Ciências sociais Hoje, Anpocs, 1984. Disponível em: https://goo.gl/VFdjdq. Acesso em: 6 out.2019

HOOKS, Bell. Amando a negritude como resistência política. São Paulo: Elefante, 2019.

HOOKS, Bell. Ensinando a transgredir: a educação como prática da Liberdade. São Paulo: Martins Fontes, 2013.

HOOKS, Bell. Intelectuais negras. Revista Estudo Feministas, v. 3, n. 2, 1995.

KILOMBA, Grada. Plantation memories: episodes of everyday racism. Munster: Unrast Verlag, 2012.

MALDONADO-TORRES, Nelson. Sobre la colonialidad del ser: contribuciones al desarrolo de un concepto. In: CASTRO-GÓMEZ, Santiago; GROSFOGUEL, Ramón (coord.). El giro decolonial: reflexiones para uma diversidad epistêmica más allá del capitalismo global. Bogotá: Siglo del Hombre Editores; Universidad Central, Instituto de Estudios Sociales Contemporáneos, Pontificia Universidad Javeriana, Instituto Pensa, 2007. p. 127-167.

MALDONADO-TORRES, Nelson. A colonialidade de cabo a rabo: o hemisfério ocidental no horizonte conceitual da modernidade. In: LANDER, E. (Org.). A colonialidade do saber: eurocentrismo e ciências sociais. Perspectivas latinoamericanas. Buenos Aires: Clacso, 2005. p. 71-103.

MIGNOLO, Walter D. Pensamento decolonial, desprendimiento y apertura. In: MIGNOLO, Walter D. (org). Habitar la frontera: sentir y pensar la descolonialidad. Barcelona: CIDOB, 2015.

OLIVEIRA, Camila Klen de. Breve introdução ao giro decolonial: poder saber e ser. 
In: SEMINÁRIO CIENTÍFICO DA FACIG, 2.; JORNADA DE INICIAÇÃO CIENTÍFICA DA FACIG, 1., Manhuaçu. Anais eletrônicos [...]. Manhuaçu: UNIFACIG, 2016. Disponível em:

http://pensaracademico.facig.edu.br/index.php/semiariocientifico/article/view/53/38. Acesso em: 29 out. 2020.

OLIVEIRA, Luiz Fernandes de; CANDAU, Vera Maria Ferrão. Pedagogia decolonial e educação antirracista e intercultural no Brasil. Educação em Revista, Belo Horizonte, v. 26, n.1, p.15-40, abr. 2010. Disponível em: https://www.scielo.br/pdf/edur/v26n1/02.pdf. Acesso em: 29 out. 2020.

PENNA, Camila. Paulo Freire no pensamento decolonial: um olhar pedagógico sobre a teoria pós-colonial latino-americana. Revista de Estudos e pesquisas sobre as Américas, Brasília, v. 8, n. 2, p.181-199, 2014.

QUIJANO, Aníbal. Colonialidad del poder y clasificación social. Journal of worldsystems research, v. 11, n. 2, p. 342-386, 2000.

RIBEIRO, Djamila. O que é lugar de fala? Belo Horizonte: Letramento, 2017.

SPIVAK, Gayatri C. Pode o subalterno falar? Belo Horizonte: UFMG, 2010.

WALSH, C. Introducion: (Re) pensamiento crítico y (de) colonialidad. In: WALSH, C. Pensamiento crítico y matriz (de)colonial: reflexiones latinoamericanas. Quito: Ediciones Abyayala, 2005a. p.13-35.

WALSH, C. La interculturalidad en la educación. Lima: Ministerio de Educación, 2005b. 